\title{
Vocal tract configuration for breathing and speech sound production
}

\section{E Fiona Bailey*}

Associate Professor, Department of Physiology, University of Arizona, USA
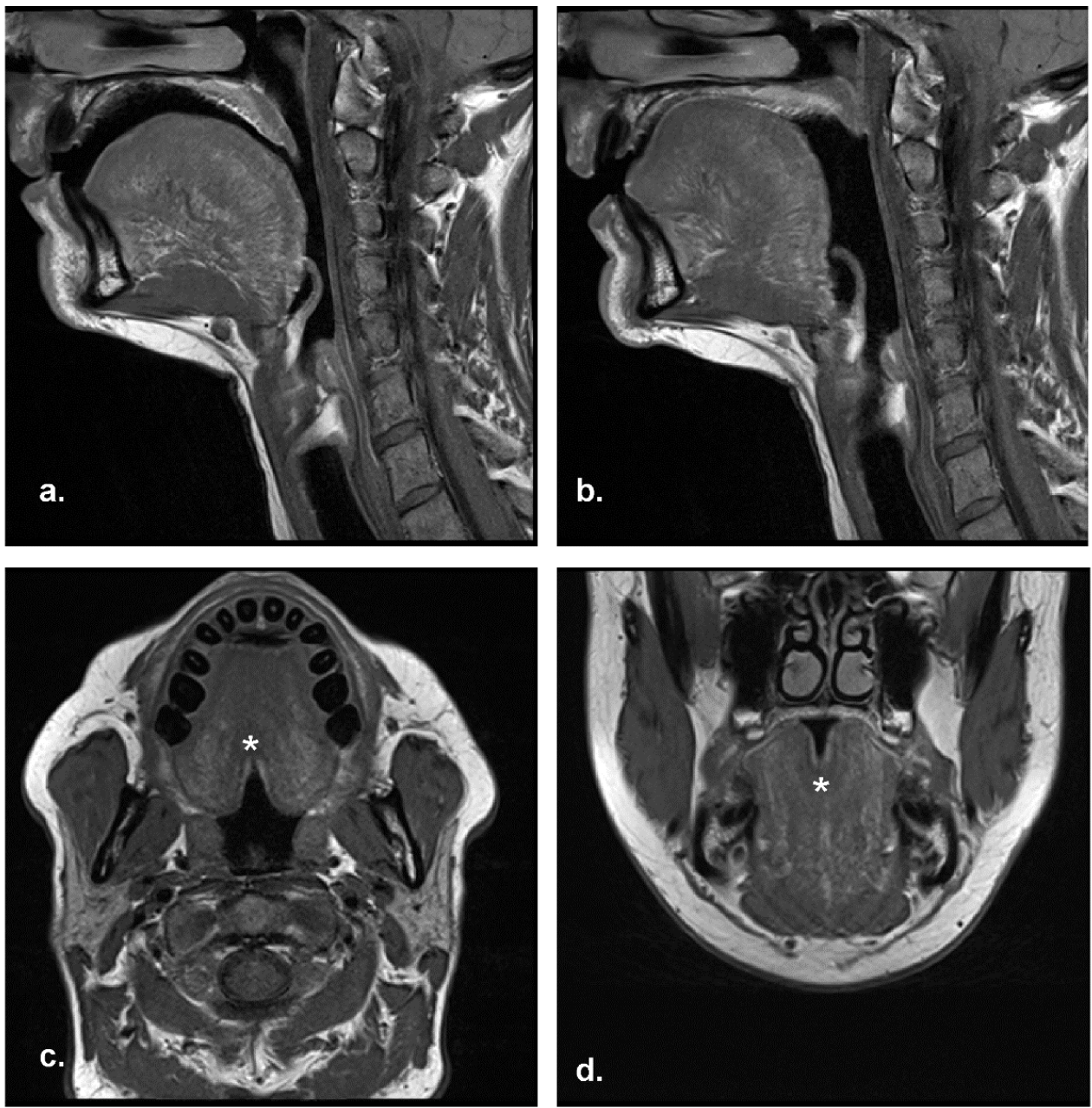

Figure 1. Magnetic resonance images of the adult vocal tract a) during rest breathing and b) during production of a sustained vowel sound. The images show compression of the tongue base and elevation of the tongue blade during production of the vowel /ee/ relative to the position of the tongue during rest breathing. Axial (panel c) and coronal (panel d) views of the oral and pharyngeal cavities highlight a central groove in the tongue, denoted an asterisk $\left(^{*}\right)$ associated with production of the vowel sound.

Copyright: (C2017 Bailey EF. This is an open-access article distributed under the terms of the Creative Commons Attribution License, which permits unrestricted use, distribution, and reproduction in any medium, provided the original author and source are credited.
Correspondence to: E Fiona Bailey, Associate Professor, Department of Physiology, University of Arizona, USA, Tel: 520-6268299; E-mail: ebailey@ email.arizona.edu

Received: November 20, 2017; Accepted: November 29, 2017; Published: November 30, 2017 